\title{
Editorial
}

Entrelazamientos e hibridaciones entre el posthumanismo y el diseño 
Antes de la presentación del contenido del número 9 de Inmaterial sentimos que es necesario referirnos a lo acontecido en nuestro país durante los últimos meses: la pandemia, la COVID-19, que ha provocado el contagio, enfermedad y fallecimiento de tantas personas que formaban parte de nuestra sociedad. Y no solo en el caso de España, sino que como pandemia ha repercutido - y está haciéndolo gravemente — también a nivel internacional. Queremos expresar nuestra solidaridad para con todas las personas, especialmente con las que han resultado directamente afectadas por el virus, así como transmitir nuestros deseos de cuidado y precaución para evitar nuevos contagios protegiéndonos individual y colectivamente. Porque, como se ha repetido durante los días de confinamiento, solo entre todas, con un esfuerzo colectivo, conseguiremos acabar con la pandemia.

\section{Entrelazamientos e hibridaciones entre el posthumanismo y el diseño}

Desde mediados de la década de 1980, el diseño ha estado dominado por un paradigma centrado en el ser humano (human-centered) y en el usuario (user-centered). Actualmente, las implicaciones de las transformaciones tecnológicas y medioambientales están desafiando a los diseñadores y diseñadoras a centrarse en sistemas sociotécnicos complejos. Este número de Inmaterial rastrea debates emergentes sobre el posthumanismo en una amplia gama de perspectivas y considera ejemplos de prácticas de diseño emergentes que enfatizan las interrelaciones entre los actores humanos y los no humanos. Los cuatro artículos que lo conforman trazan un itinerario que transita desde "Hablar con las cosas: antropomorfismo, causalidad e incertidumbre", de Alexandre Viladrich; "Erótica, vínculos e interdependencia. Diseños de cuidado", de Jaron Rowan; "Posthumanismo y búsquedas autocompletadas”, de Pablo Sánchez, hasta "La mirada tecnológica en los siglos XIX y XX: fundamentos del diseño de herramientas y metodologías basadas en el control", de Paloma González Díaz, para informar sobre el desarrollo de nuevas metodologías y prácticas en el campo del diseño y mostrar que las perspectivas emergentes en este ámbito pueden apoyar valores como justicia, igualdad, entrelazamiento, interdependencia, etc., entre diferentes actores humanos y no humanos, cuando tradicionalmente estos últimos habían sido ignorados en los procesos del diseño.

Veamos algo de lo que está ocurriendo. La crisis climática y la sostenibilidad medioambiental se han convertido en preocupaciones trascendentales y urgentes. Existen tecnologías emergentes que están reformulando la vida cotidiana y que han comenzado a desempeñar un papel importante en las 
transformaciones socioculturales, políticas y económicas actuales. Por ejemplo, en muchas ciudades alrededor del mundo ya se prueban automóviles sin conductor. Los asistentes personales activados por voz se están volviendo dispositivos domésticos comunes. Las tecnologías portátiles se empiezan a integrar en la ropa, y se crean tejidos inteligentes. Los dispositivos científico-médicos han llegado a ser tan sofisticados que algunos hasta realizan funciones que se creían solo humanas. Hay lentillas capaces de fotografiar y grabar la vida cotidiana de la persona que las utiliza con cada abrir y cerrar de párpados. Todo está cambiando a un ritmo vertiginoso.

Esos adelantos difuminan los límites de las dualidades humano y no humano, cultura y naturaleza, humano y animal que han dominado el pensamiento occidental desde la Ilustración, y subrayan las formas en que los no humanos, ya sean ambientales o tecnológicos, tienen nuevos tipos de agencia en el mundo. También revelan nuevas perspectivas y plantean preguntas sobre qué, cómo y por qué nos involucramos en el diseño de los llamados "mundos artificiales" (Broncano, 2000). En las últimas décadas, se ha desarrollado un creciente cuerpo de teoría social en torno a conceptos que intentan proporcionar nuevas herramientas hermenéuticas para hacer frente a esta confusión de límites introduciendo modos de pensamiento relacionales híbridos, no binarios, sobre el mundo. En esta edición de Inmaterial, veremos la importancia de estos modos de pensamiento híbridos, especialmente del pensamiento posthumanista, para la investigación y la práctica en diseño.

La figura híbrida de lo posthumano y los conceptos relacionados (como lo no humano, las multiespecies, el antropoceno, lo transhumano y el descentramiento de lo humano) amplían enormemente nuestra comprensión de las múltiples agencias, dependencias, enredos, entrelazamientos y relaciones que componen nuestro mundo. A medida que ajustamos nuestra comprensión fundamental del conocimiento humano y no humano y las formas de estar en el mundo, es preciso que desarrollemos también marcos, métodos y prácticas de diseño capaces de abordar mejor los desafíos que enfrentamos como planeta. ¿Qué pasa si, en lugar de comprender las necesidades de los humanos, los diseñadores y diseñadoras tienen la tarea de comprender lo que quiere o necesita un no humano? ¿Qué experiencias o teorías podrían ser necesarias para abordar este problema? ¿Qué modelos, métodos, marcos y sensibilidades pueden ser esenciales para explorar posibles soluciones? ¿Qué nuevos lenguajes (y el diseño, de eso, es buen conocedor), preguntas y alternativas podrían surgir en la búsqueda de tal proyecto? ¿Cómo podría todo ello convertirse en la base para nuevos tipos de conocimiento en diseño? Creemos que comprometerse con los conceptos de lo posthumano es el comienzo para ese debate en el campo del diseño. 
Hoy nos centramos en cuestiones igualmente relevantes como son el aprendizaje automático (machine learning), la inteligencia artificial (IA), los algoritmos (Clark, 2017), el big data, la tecnología de automatización y la robótica; métodos que se están aplicando en una amplia gama de ámbitos. Los diseñadores y diseñadoras están observando y comprendiendo sus implicaciones, y empiezan a considerarlas para la práctica del diseño. En la actualidad, existen evidencias de surgimiento de nuevas prácticas del diseño: por ejemplo, hay un creciente interés en sistemas complejos y adaptativos (Dubberly y Pangaro, 2015), en el diseño como participación (Slavin, 2016), el de futuros (Smith et al., 2016) y el de transición (Irwin, Kossoff y Tonkinwise, 2015). En su mayor parte, estas prácticas inaugurales aún se limitan a entornos de investigación académicos. Sin embargo, como se verá en los artículos que conforman esta edición de Inmaterial, algunos diseñadores y diseñadoras ya están abogando por estos enfoques al atender a las implicaciones de estas tecnologías emergentes y experimentar con ellas.

En cuanto al pensamiento posthumano, parece adecuado empezar por definir el término, aunque, como señala Rosi Braidotti (2015), el posthumanismo no es un concepto cerrado, sino más bien un índice para describir nuestro momento. El diccionario de Oxford presenta una enunciación diferenciada según se escriba el término. Por un lado, la forma "post-humanismo" (a) se refiere a 'un sistema de pensamiento articulado como reacción a los principios básicos del humanismo, y especialmente a su enfoque en la humanidad en vez de en lo divino o lo sobrenatural ${ }^{1}$. Esta definición pone el acento en los textos posmodernos y feministas, que rechazan lo racional instrumental y al individuo autónomo para enfatizar en lo común, lo situado y lo socialmente construido. Por otro lado, la forma alternativa "posthumanismo" (b), originada en la ciencia ficción en la década de 1970, se define como 'la idea de que la humanidad puede ser transformada, trascendida o eliminada, ya sea por los avances tecnológicos o por el proceso evolutivo' y, por extensión, como 'la práctica artística, científica o filosófica que refleja esta creencia ${ }^{2}$. Lo posthumano, por tanto, rechaza las categorías binarias, y en su lugar integra lo humano y lo no humano. Como tal, es un concepto importante que proporciona un punto de encuentro para pensar acerca de los sistemas sociales y tecnológicos como constructos sociales. Resulta, pues, que ambas definiciones son relevantes a la hora de comprender las teorías y supuestos que se presentan en los artículos que configuran esta edición de la revista. 
En el primero de los artículos de este número de Inmaterial, "Hablar con las cosas: antropomorfismo, causalidad e incertidumbre”, Alexandre Viladrich señala que diseñar es una acción material y simbólica porque el objeto diseñado es un elemento de consumo portador de todo un sistema de signos que tienen que ver con los significados socialmente atribuidos. Argumenta el autor que, desde el llamado "giro material" (nuevos materialismos y realismo especulativo), el mundo ya no se concibe como algo dominado exclusivamente por el ser humano en cuanto a aspectos como interpretación, discurso, textualidad, significación, ideología o poder (Cox, Jaskey y Malik, 2015). Viladrich sostiene que esta mirada posthumanista refuta lo binario y sus jerarquías, además de proponer retos y crear conflictos para el saber del diseño contemplado como actividad human-centered y material-based.

En su artículo, el autor intenta un abordaje materialista y posthumanista aplicado a la práctica del diseño, capaz de enfrentarse a la cotidiana perspicacia del marketing y de provocar un posible giro material para ese saber. Igualmente, Viladrich establece una hipótesis interesante al plantear que "el diseño reduce la mediación sujeto-objeto a una cuestión puramente cultural que falla a la hora de concebir los objetos en su ecología, como entidades aisladas del humano/a que los crea o los consume”. A razón de esa proposición, el autor sugiere un análisis causal del objeto, intentado entrelazar la agencia y la causalidad con una nueva mirada de lo matérico en relación con el diseño.

Con respecto a lo anterior, Viladrich elabora un itinerario que inicia citando a Alfred Gell (2016) y su "persona distribuida”, definiendo así la identidad que acompaña a los objetos, que son resultado del hacer de las personas, y concluye, por tanto, que la intencionalidad que define la agencia de un objeto no es autónoma, sino expresión de quien lo posee. De esta manera, los objetos se convierten para Viladrich en agentes de personalidad, es decir, en formas de "copresencia" de los agentes humanos. Siguiendo a Gell, el autor afirma que la distribución categorial entre los humanos como agentes primarios y los objetos como agentes secundarios no obsta para que estos últimos sean el centro de interés, motivo por el cual el trabajo de Gell está tan relacionado con la práctica del diseño, pues analiza la relación sujeto (humano) - objeto (de arte) en el contexto social de causalidad, que otorga valor e importancia a los objetos y a su diseño.

Continuando con la perspectiva de Gell, Viladrich señala que el diseño, en cuanto que human-made y human-centered, es una práctica antropomórfica, ya que otorga al objeto un significado, forma, uso, función e interfaces vinculados con los agentes humanos. Ello conlleva la proyección de cualidades humanas como pueden ser el apego, la intencionalidad, la agencia o la perso- 
nalidad al objeto inanimado. Todas ellas, cuestiones que no son nuevas, como asegura Viladrich al preguntarse: “¿Acaso la descripción antropológica de los objetos 'como personas' no coincide, en cierto modo, con la descripción convencional de los objetos 'para personas' propia del diseño?".

Adentrándose en el diseño posthumano y desde la idea de "hablar con las cosas", Viladrich explica que el giro posthumanista plantea una intersección para el diseño donde lo humanista y lo taxonómico del mercado se encuentra con los principios materialistas y de alteridad. El proyectar significados y valores humanos en los objetos se vincula directamente con el confort y el desarrollo vital de las personas, así como con sus placeres, y de ello resulta la gran importancia lingüística del diseño. Viladrich apunta: "Que el diseño se ocupe de mejorar y facilitar la vida de las personas no debe socavar la presencia del objeto, en su materialidad, en su propio agenciamiento, en el discurso de la disciplina. Pues, de lo contrario, se estará alejando de la ecología que hoy tanto dice pretender alcanzar".

Y concluye refiriéndose a que los objetos que el diseño lanza al mundo son auténtico lenguaje, y que este debe compartir el espacio de la mediación, de la causalidad.

"Erótica, vínculos e interdependencia. Diseños de cuidado" es un artículo de reflexión de Jaron Rowan que desarrolla el abordaje, en clave de exploración, de los límites de la tradición cartesiana, dualista, mecanicista, racionalista y positivista que ha provocado el rompimiento entre cuestiones fundamentales como la naturaleza y la cultura, los sujetos y los objetos, las artes y las ciencias o la epistemología y la ontología. Para llevar a cabo su propuesta, Rowan se sirve de la erótica como modo de establecer entrelazamientos entre humanos y no humanos mediante la creación de unos vínculos que instituyen principios de interdependencia y cuidados. La erótica es presentada como una manera de ocuparse o de cuidar de un mundo material que precisa huir de las dualidades y de las particiones causadas por la modernidad y por la racionalidad instrumental. En su texto, el autor también valora la objetividad, la crítica y la estética como formas sobresalientes de pensamiento, y pone al descubierto algunas carencias que estas mismas formas de operar generan en el diseño contemporáneo interpretado como práctica ontológica.

Rowan explica que los tres modos heredados de interrogación de la realidad (objetividad, crítica y estética) son cuestionados hoy por los sistemas epistémicos hegemónicos, sea desde la ontología orientada al objeto, desde los nuevos materialismos, desde la división ontológica sujeto/objeto, o bien desde los feminismos. Todos los cambios en el hacer y pensar el mundo se 
encuentran ya en el contexto del diseño, donde diferentes autores invitan a profundizar en un diseño que promocione las interdependencias y la creación de pluriversos.

El autor apuesta por la erótica, un modo de pensar/hacer que posibilite recuperar y unir algunas de las fracturas epistémicas recibidas como legado de la modernidad, y propone una serie de disposiciones que nos conduzcan a entrelazarnos y crear intimidades con objetos, plantas, minerales y animales. Se trata de una vindicación de la erótica como perseverancia y firmeza del ánimo impulsora de salir de uno mismo, abandonar el yo y entender que siempre hemos sido un "nosotros". Una erótica que diluye las líneas entre el yo y el mundo, convirtiéndose en un avance para acabar con la separación ficticia que hemos creado entre los individuos y el mundo y aceptar, al fin, que solo podemos ser con lo y los demás. Siempre hay transgresión en la erótica, señala Rowan citando a Bataille (2013), pues, entendida epistémicamente, esta ilumina relaciones o puede volverse un artefacto de presión al mostrar la coexistencia de interdependencias y legitimando modos de posesión. De ahí que la erótica sea tan peligrosa, y de ahí también que implique transgresión. Sin embargo, en un contexto capitalista, la erótica y su tensión devienen mercancía.

Situándose en el diseño ontológico, Rowan afirma que el diseño es una práctica que crea mensajes, objetos y experiencias, pero que precisamente por ello contribuye también a crear los mundos en los que existen esos mismos objetos, mensajes, experiencias y sensaciones. El autor defiende que las prácticas críticas de diseño han de imaginar los mundos que colaboran a crear y responsabilizarse de ellos, porque crear objetos implica establecer relaciones de cuidado. Ello significa aceptar formas de subjetividad nacidas del entrelazamiento y la interdependencia, dejando de lado la autonomía e independencia de tipo liberal. Este es el contexto en el que el autor propone el diseño como erótica; ese que admite modos de conexión, vínculos, entrelazamientos, es decir, "el diseño entendido como una manera de hacer mundos, pero también de cuidarlos”. Rowan finaliza su artículo afirmando que la erótica nos conduce a encontrar formas de recomponer todos los vínculos con los objetos, sujetos y mundos, a "cuidar el mundo que somos, un poco más".

En el tercero de los artículos, "Posthumanismo y búsquedas autocompletadas", de Pablo Sánchez, se quieren poner de manifiesto algunos desafíos de la visión del posthumanismo planteado por Braidotti (2009), en contraposición al humanismo, y establecer entrelazamientos con el diseño digital para llevar a cabo el planteamiento de una propuesta de un espacio ético-político compatible con la mirada de la autora sobre la época del antropoceno. 
Desde la otredad de Braidotti en relación con "los otros sexualizados (las mujeres), los otros racializados (los nativos) y los otros naturalizados (los otros animales, el medioambiente o la Tierra)", Sánchez cuestiona si hay que exigir la igualdad, algo que parecería un posicionamiento deseable para la mayoría de la sociedad, siguiendo también los postulados que en ese sentido presenta la filósofa. El autor se pregunta qué significa esa exigencia en un escenario humanista, donde se jerarquizan las diferencias para convertirlas en excluyentes. Además, en la actualidad hay una variedad de otredades que evidencian la crisis del modelo antropocentrista. Así, es posible hablar de lo no humano o de lo otro artificial refiriéndonos a las identidades tecnológicas creadas por los humanos, basadas en el machine learning y que llevan a cabo elecciones y decisiones que afectan a todos los individuos. O del cíborg (Haraway, 1995) como un sujeto híbrido, mezcla de carne y máquina, que provoca una intensa reflexión acerca del cuerpo. El concepto de otredad, pues, nos lleva a entrever la caducidad antropocéntrica y el valor del individualismo también caduco para avanzar y pensar, o, como dice Sánchez siguiendo a Braidotti, para especular sobre el sujeto desde una perspectiva relacional, nunca unitario, sino definido a través de procesos de transición y cruces de fronteras, porque el individualismo genera la emergencia del egocentrismo y del egoísmo, que pueden convertirse en dominación.

Vinculado con lo anterior, Sánchez alude a la constatación de que la ciudadanía admite sin reservas no sentirse representada dentro de los parámetros de una democracia liberal, lo cual descubre una crisis de legitimidad política ya grave por sí misma y que, a su vez, evidencia la existencia de una serie de fenómenos como la crisis climática, las crisis económicas, las crisis migratorias, los conflictos bélicos, etc., que el modelo actual no aborda eficientemente. El autor afirma que los artefactos y dispositivos ético-políticos fundamentales para crear una sociedad justa deben basarse en la "capacidad de creación de una subjetividad relacional ecodependiente e interdependiente, consciente y localizada”. Y añade: "Estos dispositivos deberán ser públicos, accesibles y abiertos si queremos evitar que el capitalismo y sus prácticas marquen la agenda de actores tan importantes como la tecnología o la ciencia”.

De esta manera, en cuanto a las formas de gobernanza, según continúa diciendo Sánchez, "las únicas que pueden garantizar al posthumanismo una subjetividad relacional ecodependiente, interdependiente, consciente y localizada son aquellas que buscan la creación de espacios no jerarquizados y con ausencia de coerción y, por lo tanto, también de concentración de poder”. Deben ser espacios de libre asociación y autoorganización, asegura el autor, porque los movimientos que emergen de esas realidades, huyendo de las rígidas construcciones institucionales, buscan lo colectivo como un espacio de 
desarrollo desde donde crecer o decrecer, es decir, ser proceso. Precisamente en este contexto es donde se ubican algunos procesos de diseño y desarrollo de software libre y open source o código abierto. La filosofía fundamental de ese movimiento de software libre alude de manera constante a la ética (referida al modo de entender los programas de ordenador, su distribución y uso), explica el autor, y lo ilustra desplegando una amplia variedad de ejemplos, entre los que no olvida mencionar el sesgo de género presente en los equipos de diseño y en los productos resultantes. Más adelante, Sánchez argumenta que quizá uno de los temas más irritantes sea el de los algoritmos, ya que a fin de cuentas son ellos los que deciden los resultados de nuestras búsquedas: el qué, el cómo y el cuándo. Y esos algoritmos, pese a carecer de cuerpo, tienen internalizado un lenguaje claramente masculino, pues en las cinco mayores empresas tecnológicas del mundo, la práctica totalidad de los trabajadores son hombres. El autor se pregunta, entonces: ¿cómo rastrear algo que no tiene cuerpo?

A través de un recorrido por lo que Sánchez denomina la "civilización de la información”, hoy nos encontramos con formas coercitivas que son casi imperceptibles: sugerencias, feeds interminables, noticias falsas, búsquedas autocompletadas, mensajes que manipulan sutilmente las conductas de los individuos... Se trata de dispositivos de control digital que compilan datos derivados de las prácticas humanas y generan estándares de predicción, los cuales, a su vez, actúan transformando los comportamientos humanos. Como expone el autor citando a Deleuze (1990), así entramos "en un régimen de control", donde "nada se termina nunca". En todos esos constructos tecnológicos, el rol de la persona que diseña es vital, así como el de todos aquellos especialistas implicados en el diseño de un producto tecnológico. De esta manera, diseñadores y diseñadoras deben aceptar su responsabilidad en el reto posthumanista y plantear diseños que garanticen la subjetividad ético-política de seres ecodependientes e interdependientes, localizados y autoorganizados en procesos sostenibles. Sánchez concluye señalando que un reto importante es que los propios diseñadores y diseñadoras comprendan que son capaces de crear esas herramientas sociales y, en última instancia, lo hagan.

Enlazando con la idea de control, nos adentramos en el artículo de Paloma González Díaz, "La mirada tecnológica en los siglos XIX y XX: fundamentos del diseño de herramientas y metodologías basadas en el control”. Precisamente, este texto nos aporta una medida visión de cómo se inició el proceso de lo que Sánchez denomina "civilización de la información”. González apunta que es a lo largo de los siglos XIX y XX cuando se piensan, diseñan y desarrollan las herramientas y los métodos que habrán de cambiar la forma de ver y aprehender el mundo. Nacerá entonces una mirada tecnológica que suplirá la visión del entorno del ser humano, y se recuperarán los principios 
de control discurridos y planteados por Bentham en su panóptico (1979), un sistema utilitarista propuesto para transformar el sistema carcelario.

$\mathrm{Al}$ inicio, en el proceso de diseño e implementación de esos nuevos modelos de uso vinculados con una visión tecnificada, actúan investigadores y teóricos de diferentes ámbitos, tal como explica González. Sin embargo, dada la importancia de los resultados conseguidos en indagaciones realizadas por científicos, fotógrafos e inventores acerca de herramientas y técnicas, finalmente serán los gobiernos los que se interesarán por perfeccionar y acrecentar las posibilidades de algunas propuestas, aunque con el objetivo de utilizarlas como sistemas de defensa y control. No obstante, a causa de los costes de desarrollo y explotación de las tecnologías relacionadas con la mirada, y una vez utilizadas estas en trabajos militares, dichas propuestas acostumbran a evolucionar para convertirse en herramientas de uso habitual. De modo que en muchas ocasiones, argumenta la autora, la experiencia alcanzada con esas tecnologías, junto con la labor de apropiación y exploración llevada a cabo por diseñadores y artistas, contribuyen a adaptar e instaurar esos dispositivos tecnológicos en tareas creativas.

Refiriéndose a una nueva mirada tecnificada del entorno, González habla de la fotografía como cimiento de la tecnología de vigilancia y control, especialmente a mediados del siglo XIX, cuando se inicia la fotografía aérea. Con el transcurso del tiempo se llegará a la "democratización" de la fotografía, que a su vez conllevará la aparición de nuevas metodologías de control, solo que ahora invisibilizadas por el uso social de esta tecnología en forma de divertimento para artistas y científicos. Así, la fotografía acabará tornándose objeto de consumo en la sociedad del siglo XX, sobre todo por su gran facilidad de utilización, puesta de manifiesto con el eslogan de Eastman: "You press the button, we do the rest" (Ford, 1988). Este proceso de democratización social, según explica González, encubre otro tipo de intereses y prácticas, conducentes al diseño de la sistematización del control tecnológico con el objetivo de catalogar y excluir al diferente. Por ejemplo, se elaboran registros antropométricos que miden cuidadosamente las diferentes partes del cuerpo y establecen estándares; se investiga sobre el uso de huellas dactilares o sobre un método de identificación basado en el estudio de los pliegues de las orejas. Todos estos experimentos contribuyen a crear, según la autora, lo que Foucault denominó "tecnologías del sujeto", "entendidas estas como la aplicación científica de los dispositivos técnicos para un eficiente y sistemático control social”.

Otro dispositivo desarrollado con fines militares que transforma la visión del entorno es el equipo portátil de vídeo, aparecido a finales de los años sesenta. González expone que el objetivo que guió su creación fue su uso en 
viajes espaciales, aunque su aceptación social como producto de consumo era especialmente buena, sobre todo en ambientes creativos próximos a la producción audiovisual. De acuerdo con la autora, este nuevo artefacto se convierte en la época "en la respuesta al centralismo, al inmovilismo y al control televisivo imperante en [...] el Mayo del 68”. Por otro lado, los medios de comunicación de masas empiezan a valorar la eficacia de las herramientas de origen militar como radares, radios, satélites, cámaras digitales y teléfonos móviles, y precisamente debido a esa valoración de la tecnología por parte de los medios, términos de origen castrenses como "bombas inteligentes" o "daños colaterales" se introducen rápidamente en el vocabulario cotidiano. Así, las cámaras y sensores se van posicionando en función de los objetivos por los que son ideados, con el fin de crear una visión tecnificada que sustituya a la visión humana. Por ejemplo, se lleva a cabo el registro de intervenciones de bombardeo en imágenes de enorme espectacularidad que alcanzan una gran difusión, y cuya estética es veloz y acríticamente asumida por una audiencia que lo entiende como el nuevo paradigma de la información de actualidad.

González señala que son los diseñadores y artistas los primeros en inundar la red con sus obras críticas. Aparecen herramientas de diseño, como Photoshop, y se populariza el formato GIF, que ofrece a creadores y diseñadores la posibilidad de añadir dinamismo a sus mensajes. "La contemplación tecnificada se expande — explica la autora - y se impone a la visión natural del ojo. Los programas de reconocimiento y procesamiento de imágenes suplantan definitivamente el papel de testigo veraz de los hechos producidos.” Además, las imágenes grabadas también se hacen con objetivos promocionales, lo cual impulsará el inicio de una nueva tendencia: el uso de drones. Toda la tecnología pensada para usos militares se disemina hasta impregnar a la industria civil; según la autora, ese hecho provocará "el desarrollo y abaratamiento de algunas de las tecnologías que más impacto han tenido en el inicio del siglo XXI, por ejemplo, las cámaras digitales, la inteligencia artificial, la robótica o la realidad virtual".

A modo de conclusión, González indica que tras la guerra del Golfo se impuso una estética de la espectacularidad y del simulacro que fue aprovechada por los mercados del videojuego, la realidad virtual o la inteligencia artificial para trasladar a la sociedad las técnicas y estrategias antes ubicadas en el ámbito militar. Por último, la autora destaca que a la gestión de datos (resultado de la evolución de la informática, la interconexión entre sistemas y la convergencia de medios que se entrevé a corto plazo) se une la estandarización de herramientas y de trabajos para el desarrollo de proyectos audiovisuales, de manera que tanto el diseño como la creación devienen ámbitos básicos en la lucha contra la arbitraria normalización del mercado audiovisual. 
A través del breve itinerario desplegado en este editorial — pero, sobre todo, en los artículos que pueden leerse en las páginas siguientes-, se evidencian los múltiples entrelazamientos e hibridaciones entre el posthumanismo y el diseño. Un trazado que pone de manifiesto que el diseño habla con las cosas estableciendo vínculos desde la erótica y el cuidado, a la vez que desvela que la tecnología proporciona búsquedas autocompletadas por algoritmos invisibilizados y que todo ese conjunto tiene unos orígenes precisos, derivados de usos impensables basados en el control de los individuos. Estas son algunas de las cuestiones que en la actualidad son contestadas por la mirada transformadora y proponedora del posthumanismo entrelazada con el diseño. 


\section{Bibliografía}

Bataille, G., 2013. El erotismo. Barcelona: Tusquets.

Bentham, J. y Foucault, M., 1979. El panóptico / El ojo del poder. Madrid: La Piqueta.

Braidotti, R., 2009. Transacciones: transponer la diferencia. En: Transposiciones. Barcelona: Gedisa.

Braidotti, R., 2015. Lo posthumano. Barcelona: Gedisa.

Broncano, F., 2000. Mundos artificiales. Filosofía del cambio tecnológico. México: Paidós.

Clark, J., 2017. Design in the Era of the Algorithm. [en línea] Big Medium. Disponible en:

$<$ https://bigmedium.com/speaking/design-in-the-era-of-the-algorithm.html> [Consultado: junio de 2020].

Cox, C., Jaskey, J. y Malik, S., 2019. Realism Materialism Art. Berlín: Sternberg Press.

Deleuze, G., 1990. Conversaciones. Valencia: Pre-Textos.

Dubberly, H. y Pangaro, P., 2015. How Cybernetics Connects Computing, Counterculture, and Design. En: A. Blauvelt y R. Elfline, eds. 2015. Hippie Modernism: The Struggle for Utopia. Mineápolis: Walker Art Center.

Ford, C., 1988. You press the button, we do the rest: the birth of snapshot photography. Londres: D. Nishen Pub.

Gell, A., 2016. Arte y agencia. Una teoría antropológica. Buenos Aires: SB Editorial.

Haraway, D.J., 1995. Ciencia, cyborgs y mujeres. La reinvención de la naturaleza. Madrid: Cátedra.

Irwin, T., Kossoff, G. y Tonkinwise, C., 2015. Transition Design Provocation. Design Philosophy Papers, 13, n. ${ }^{\circ}$, pp. 3-11.

Slavin, K., 2016. Design as Participation. Journal of Design and Science, [en línea] I, n. ${ }^{\circ} 1$. Disponible en: $<$ https://jods.mitpress.mit.edu/pub/design-as-participation/release/1> [Consultado: junio de 2020].

Smith, R. C. et al. (eds.), 2016. Design Anthropological Futures. Nueva York: Bloomsbury.

The Oxford English Dictionary, 2020. The Oxford English Dictionary Online. [en línea] Oxford: Oxford. Disponible en: <https://en.oxforddictionaries.com> [Consultado: junio de 2020]. 
Editoras del número:

Mara Martínez Morant Doctora en Antropología Cultural y Social por la Universidad de Barcelona. Profesora e investigadora en Bau, Centro Universitario de Diseño de Barcelona, donde imparte la asignatura Antropología Sociocultural y es miembra de GREDITS (Grup de Recerca en Disseny i Transformació Social). Sus investigaciones giran en torno a cuestiones vinculadas con el cuerpo, tanto humano como de otros animales, enmarcado en la perspectiva posthumanista. Autora de trabajos como: Reflections on Anthropology and Design. My Desk is my castle. 2011. Exploring Personalisation Cultures. Basel: Birkhäuser; Experimentar el embarazo y el aborto. 2013. En: Maternidades, procreación y crianza en transformación. Bellatera: Barcelona; Veganismo ¿una identidad social emergente? Congreso Internacional de Antropología, Barcelona, 2016. Investigaciones pendientes de publicación (2020 y 2021): Del parentesco con los otros animales (UOC) y Etnografía de las interrelaciones animales (IMF/CSIC).

Ramon Rispoli Licenciado en Arquitectura por la Università degli Studi di Napoli "Federico II" y doctor acreditado en Historia de la Arquitectura y del Urbanismo por el Politecnico di Torino (Italia). Actualmente es profesor titular en BAU Centro Universitario de Diseño de Barcelona, donde imparte la asignatura de Estética y Teoría de las Artes en el marco del Grado en Diseño. Es miembro de GREDITS (Grup de Recerca en Disseny i Transformació Social). En sus investigaciones se ocupa principalmente de cuestiones de teoría del diseño y de la arquitectura, con especial atención a sus dimensiones estéticas y políticas. Es autor de dos monografías, además de ensayos y artículos publicados en revistas científicas y volúmenes colectivos. Ha participado como ponente en conferencias y seminarios internacionales, $\mathrm{y}$ ha realizado estancias de investigación en centros como el Centre Canadien d'Architecture (Montréal, Canada) y el Getty Research Institute (Los Angeles, USA). 